\title{
Emergency medical response strategy proved critical to sustaining Georgia's health infrastructure
}

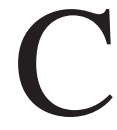

all it the sort of painful experience that few wish for, but once gained is invaluable.

Georgia's long and troubled history at the crossroads of clashing civilizations came in handy when a humanitarian crisis emerged overnight with the start of fighting with its northern neighbour Russia on Aug. 7, 2008.

In fact, the health minister of Georgia says the reality of serving as battlegrounds for everyone from the Roman Empire to the Soviet Union was integral to his nation's ability to sustain its health care system following the brief war with Russia.
Despite bombed medical buildings, looted supplies and a large displaced population, past experience taught the nation to respond with a measure of determination and quickness, says Health Minister Alexander Kvitashvili.

More recently, the Georgians garnered practical lessons from the 1991-92 South Ossetia War. When fighting broke out over the state's declaration of independence, Georgia made several key errors in responding to the medical crisis that today's leaders were determined not to repeat.

"We had the experience of conflict in 1991 and '92 and the chaos that hap-

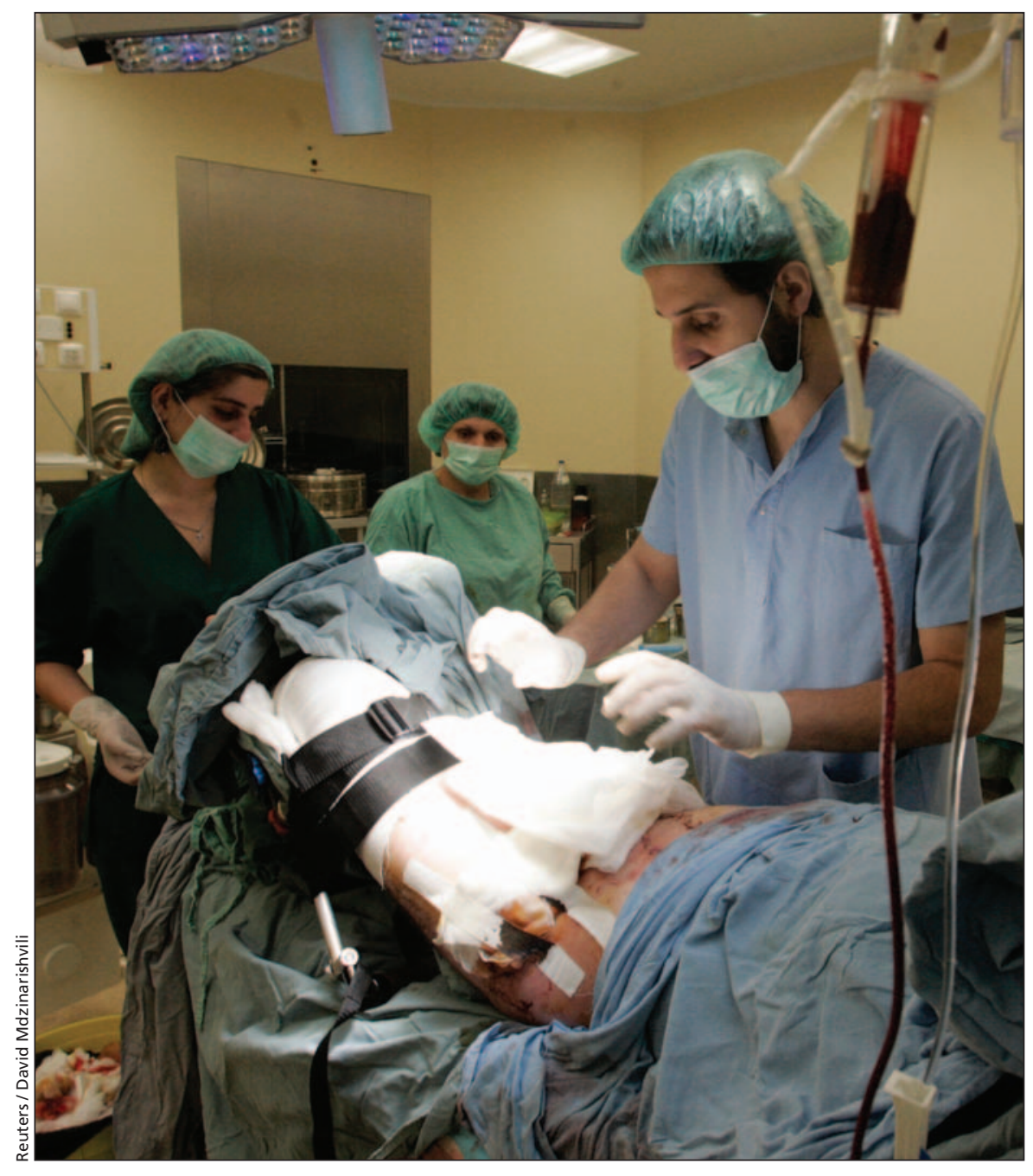

A man receives medical treatment at a hospital in Tbilisi, the capital of Georgia, after being injured during Russia's occupation of the country following the brief war over the pro-Moscow province of South Ossetia. pened then," says Kvitashvili. "In '92 the health minister was wearing camouflage — and on the front lines — which created fear."

In its response to the fighting, every hospital continued accepting patients, which left workers, and knowledge, scattered across the country at a time when communication was not easy.

"There was no plan then. There was no coordination," Kvitashvili says. "As a result, you have no idea who is where, and the patient ends up in facilities that do not have appropriate services."

By contrast, when the fighting broke out in August 2008, a field hospital was set up close to the fighting near South Ossetia to stabilize the wounded before they were sent to a military hospital in Gori, the nearest city outside South Ossetia and a hub for east-west travel in Georgia, for further treatment and assessment. From there, the wounded were sent to 1 of 3 hospitals in the country's stable regions. In all, the system processed about 2400 patients in the first 2 weeks of conflict.

The initial response, focused on handling a sudden influx of wounded and displaced, quickly evolved into the early stages of a rebuilding and resettlement campaign.

As part of that, officials began assessing the state of the country's health care infrastructure. Government figures show 17 outpatient facilities, 1 hospital and 3 ambulance centres were lost in the fighting, representing about $4 \%$ of health care facilities. Others were damaged or looted but can be repaired or restocked.

"There has been limited damage to the actual health infrastructure, so that at least provides a solid starting point," says Chris Skopec, Georgia team leader for the International Medical Corps. "But still it is a fairly massive undertaking and Georgia may remain in the crisis period for some time."

International experts say the domestic leadership in the emergency response was key to maintaining a functional health care system throughout the fighting. 
"What distinguishes the situation here is that there is such a strong commitment from the government to really manage and take care of the situation," says Gerald Rockenschaub, a regional advisor with the World Health Organization (WHO). "We don't always see that in other conflict situations."

But all assessments come with the important caveat that few have been granted access to Russia-controlled South Ossetia in northern Georgia. Moscow now recognizes South Ossetia as an independent state along with Abkhazia in western Georgia.

Also of concern is maintaining the health of the estimated 150000 who fled the war zone. The fact that much of the population was healthy prior to the conflict made them better equipped to handle the instability, and the government is providing free health care for those displaced by fighting.

The government and aid workers also scrambled to maintain access to food, water and sanitation facilities for the displaced. The 200 medical workers displaced by the fighting were deployed to the temporary collection centres, which were typically located in schools. Of those who fled, at least 10000 had returned by the start of September 2008, and all but 25000 are expected to go home within 6 months. The government will build prefab housing settlements outside Gori for those who remain displaced.

That Georgia's health care infrastructure is not as sophisticated as those in Europe or North America may play to the country's advantage. Many of the outpatient clinics were basic cinder block structures, some no bigger than $75 \mathrm{~m}^{2}$.

In all, the government estimates the relief effort cost it about US\$3.5 million. An equivalent amount is expected to be spent on resettlement and rebuilding efforts. The United Nations has called for US\$7.7 million from donors to help pay for its health and nutrition response to the crisis in Georgia.

The nation's medical system has come a long way since the early 1990s. Following independence from the Soviet
Union in 1991, Georgia suffered through 2 civil wars that displaced some 350000 .

That fighting, and the collapse of Soviet trade, sent the Georgian economy into a death spiral. By 1993, infla-

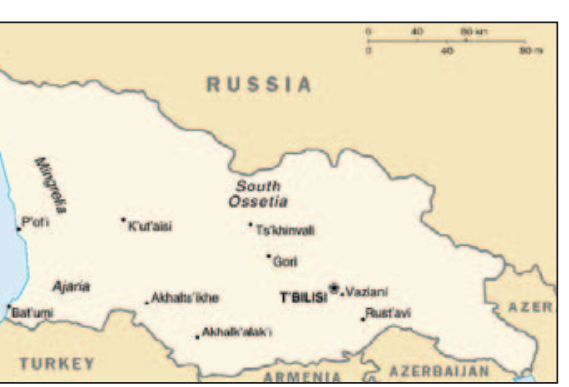

tion reached $8400 \%$ and by 1994 , annual public expenditure on health was down to US\$0.81 per person.

Today, however, it is a different story. Georgia's economy has rebounded and as a result its infrastructure stabilized. The state spends about US\$123 per capita on health care, according to WHO figures. Georgia has 47 doctors per 10000 citizens, more than double Canada's ratio.

Boosted state funding has come with a larger role for private medicine - the state funds only about $20 \%$ of Georgia's health care system - meaning most medical care is delivered through a series of user fees. As part of efforts to push citizens towards private care, the government funds health insurance for some 800000 Georgians, out of its 4.6 million population.

The longer-term recovery efforts will certainly lead to difficult decisions as Georgia rebuilds its infrastructure.

In the meantime, though, a sense of pride is emerging in a country whose soil has long been trod by foreign powers but seems to have emerged, if not unscathed, at least in one piece from the latest conflict.

"Everyone here is very proud," says Kvitashvili. "The state functioned as the state, the government functioned as the government and the country did not fall apart. It's a good feeling to realize that we made it as a state and it's good for the population to see that." - Christopher Mason, Ottawa, Ont.

DOI:10.1503/cmaj.081447

\section{Briefly}

Prostrate screening: The United States Preventive Services Task Force is recommending that physicians discontinue routine prostate cancer screening of men over 75 because the harms outweigh the benefits (www .ahrq.gov). The harms of screening include discomfort and stress, while the harms of treatment include "erectile dysfunction, urinary incontinence, bowel dysfunction, and death. A proportion of those treated, and possibly harmed, would never have developed cancer symptoms during their lifetime," stated the task force.

Work benefits: An Australian Bureau of Statistics study (www.abs.gov.au /ausstats) indicates that continued participation in the labour force trumps retirement as older workers have significantly lower rates of arthritis and cardiovascular disease than do the unemployed and retirees between the ages of 45 and 74.

Racial divide apology: The American Medical Association has issued an apology "for its past history of racial inequality toward African-American physicians," after releasing the findings of its internal study into organized medicine's racial divide (www.amaassn.org). On Jul. 30, 2008, Immediate Past President Dr. Ronald Davis told the National Medical Association, which represents black physicians, that the 2 associations should "stand as one" for equal access to quality care, elimination of disparities, diversity in the physician population, as well as cultural competency training for all students, residents and fellows.

Yaounde declaration: Health ministers from the 25 countries in the African Meningitis Belt have committed themselves to a new meningtis prevention and control strategy that includes the administration of a new candidate meningococcal A conjugate vaccine to a proposed 23 million infants and 250 million Africans aged 1 to 29. Wayne Kondro, CMAJ

DOI:10.1503/cmaj.081415 